\title{
ASSESSMENT OF ANTIMICROBIAL AND ANTIOXIDANT ACTIVITIES OF A SPECIES OF ASPERGILLUS: AN ENDOPHYTIC FUNGUS OF SCHIMA WALLICHII (DC.) KORTH. LEAVES
}

\author{
SUNRIT BASU SARBADHIKARY, NARAYAN C MANDAL* \\ Department of Botany, Mycology and Plant Pathology Laboratory, Visva-Bharati, Santiniketan, West Bengal, India. \\ Email: mandalnc@rediffmail.com
}

Received: 01 May 2017, Revised and Accepted: 10 June 2017

\section{ABSTRACT}

Objective: The main goals of this study were to check the antimicrobial and antioxidant potentials of an endophytic fungal strain isolated from the leaves of Schima wallichii (DC.) Korth.

Methods: The antibacterial and antifungal activities of the isolated fungal endophyte Visva-Bharati endophyte fungal (VBEF2) were checked by disc diffusion and agar well diffusion methods, respectively, against six pathogenic bacteria and four pathogenic fungi. The minimum inhibitory concentration (MIC) values and the mode of action of VBEF2 against Gram-positive Staphylococcus aureus and Gram-negative Escherichia coli were determined following colony-forming units (CFU) counting method. Antioxidant activity of the isolate was studied following 2, 2-diphenyl-2picrilhydrazyl (DPPH) reduction assay.

Results: The cell-free supernatants (CFS) of VBEF2 exhibited excellent antibacterial activity against all the bacteria used. The ethyl acetate extract of the endophyte was found to have the MIC of $50 \mu \mathrm{g} / \mathrm{ml}$ and $150 \mu \mathrm{g} / \mathrm{ml}$ against $S$. aureus and E. coli, respectively. It showed bactericidal mode of action against both of them. The CFS of the strain VBEF2 also showed excellent activities against two animal and two plant pathogenic fungi by producing zones of inhibition in the range of $10-20 \mathrm{~mm}$. In the DPPH scavenging antioxidant assay, the ethyl acetate extract of VBEF2 was found with a low IC ${ }_{50}$ value of $19.01 \mu \mathrm{g} / \mathrm{ml}$. The strain VBEF2 was identified as a species of Aspergillus based on its colony morphology and structural features observed under a compound light microscope.

Conclusion: The strain VBEF2 can be implemented in various fields of pharmaceutical industry as it showed multidimensional beneficial attributes such as excellent antimicrobial and antioxidant activity.

Keywords: Schima wallichii, Endophyte, Antimicrobial activity, Minimum inhibitory concentration, Bactericidal, Antioxidant activity.

(C) 2017 The Authors. Published by Innovare Academic Sciences Pvt Ltd. This is an open access article under the CC BY license (http://creativecommons. org/licenses/by/4. 0/) DOI: http://dx.doi.org/10.22159/ajpcr.2017.v10i9.19501

\section{INTRODUCTION}

Endophytes are microorganisms that colonize the plant tissue without causing any adverse effect or producing symptoms on the plant [1]. Several fungi, bacteria, and actinomycetes have been reported as endophytes previously [2], and the fungal members are most common and frequently isolated from several plants [3-7]. Endophytes play several beneficial roles for their host plants like they can produce innumerous secondary metabolites [8] which shield the host from the pathogens, involve in the mineralization process, and add nutritive value. Endophytes can also produce many precursor molecules of plant metabolism and bioactive compounds which are generally found in the crude drugs like 'Taxol' [9]. Isolation of an endophyte with specific function thus definitely helps in the production of a desired compound or drug in a large scale and the practice is also a less timeconsuming procedure. Till now, several endophytes are reported having excellent antimicrobial and antioxidant activities [10-12]. Tripura is a small state and located in the North Eastern part of India. The state represents huge floral diversity with different ethnic groups [13]. Schima wallichii (Theaceae) is an indigenous plant of Tripura whose different parts specially leaf is traditionally used by the local people in many medical problems. The leaf paste of it is generally used by the ethnic people for healing cuts and injuries. They also use the leaf decoction for curing flatulence. In our previous study, we reported the leaves of $S$. wallichii (Theaceae) to show excellent antimicrobial as well as antioxidant activities which were collected from Udaipur, Tripura [14]. The present study describes the isolation of endophytic fungi from the leaves of $S$. wallichii and their antimicrobial and antioxidant potentials.

\section{METHODS}

Isolation of the endophytes

Fresh leaves of $S$. wallichii were collected from Tripura and were carefully brought to the mycology-plant pathology laboratory, VisvaBharati. Healthy leaves were washed in the sterilized water, and the laminas were cut into small pieces with sterilized scissor under aseptic condition. Next, the leaf pieces were surface sterilized using $4 \%$ sodium hypochlorite $(\mathrm{NaOCl})$ for 5-7 minutes followed by 70\% ethyl alcohol for 4-5 seconds. After washing in sterilized water and mild drying, the leaf pieces were placed in the malt extract agar (MEA) plates containing $2 \%$ agar-agar for the isolation of the endophytic fungi. Streptomycin $(100 \mu \mathrm{g} / \mathrm{ml})$ was mixed in the isolating medium for avoiding the bacterial contamination. The plates were then incubated at $28^{\circ} \mathrm{C}$ for the appearance of fungal mycelium.

\section{Identification of the endophyte}

The endophytic strain VBEF2 was identified both by noticing its colony nature in MEA plate and its morphological characteristics under compound light microscope. VBEF2 was properly grown on MEA Petri plate till the prominent mycelial growth. Next, the mycelia were stained with cotton blue and lactophenol and identified by observing its structural morphology under both low-power $(\times 10)$ and high-power $(\times 40)$ magnifications.

Antibacterial potential of the endophyte

Antibacterial range of the endophytic fungal isolate Visva-Bharati endophyte fungal (VBEF2) was carried out using disc diffusion method [15]. Its antibacterial efficiency was checked against three Gram- 
negative pathogenic bacteria, namely, Escherichia coli MTCC1667, Salmonella typhimurium MTCC98, and Pseudomonas aeruginosa MTCC741 and three Gram-positive bacteria, namely, S. aureus MTCC96, Bacillus subtilis MTCC121, and Listeria monocytogenes MTCC657. The strains were procured from Microbial Type Culture Collection (MTCC), IMTech, Chandigarh, India. VBEF2 was cultured in ME broth at $28^{\circ} \mathrm{C}$ and after its proper growth, paper discs $(6 \mathrm{~mm}$ in diameter) of Whatman No. 1 filter paper soaked with the cell-free supernatants (CFS) of the VBEF2 culture were placed over the pathogenic bacterial lawn in the nutrient agar (NA) plates. In this assay, positive and negative controls used were ciprofloxacin $(10 \mu \mathrm{g} / \mathrm{ml})$ and sterilized dimethyl sulfoxide (DMSO), respectively. The plates were incubated at $35-37^{\circ} \mathrm{C}$ for $24 \mathrm{hrs}$.

\section{Minimum inhibitory concentration (MIC) of the ethyl acetate fraction of the endophyte}

As VBEF2 showed good antibacterial efficiency, its MIC values against one Gram-positive and one Gram-negative bacteria, i.e., $S$. aureus and E. Coli, respectively, were determined. The CFS of VBEF2 was extracted with $40 \%$ ethyl acetate. After proper drying of the extract, different concentrations of it, namely, 25, 50,100,150, and $200 \mu \mathrm{g} / \mathrm{ml}$ were prepared in DMSO. These different concentrations were added to respective test tubes containing NB and fixed volume of bacterial culture. Next, the test tubes were incubated at $37^{\circ} \mathrm{C}$ for overnight. After proper incubation, $100 \mu \mathrm{l}$ of each bacterial culture were spread on the NA plates with proper dilution. Finally, the plates were again incubated at $37^{\circ} \mathrm{C}$ for overnight and the MICs were calculated by CFU counting method.

\section{Mode of action of the endophyte}

The mode of action of the ethyl acetate extract of VBEF2 against $S$. aureus and E. coli was determined following time-kill study. Two simultaneous experimental sets for each bacterium were run as control and treated set. The ethyl acetate extract of VBEF2 was added in the actively growing cultures of $S$. aureus and E. coli at its MIC values in the treated sets. CFU for successive $10 \mathrm{hrs}$ from both sets of each bacterium was recorded to determine the mode of actions of the extracts [16].

\section{Antifungal efficiency of the endophyte}

The antifungal activity of VBEF2 was checked by agar well diffusion method [17] against two plant pathogenic fungi, namely, Helminthosporium compactum MTCC351 and Alternaria alternata VBAV007 and two animal pathogenic fungi, namely, Candida albicans MTCC1644 and Aspergillus parasiticus MTCC2796. The fungal strains were taken either from the Mycology and Plant Pathology Laboratory, Visva Bharati, India or procured from MTCC, IMTech, Chandigarh, India. Pathogenic fungal cultures $(100 \mu \mathrm{l})$ were spread on the respective MEA plates, in which wells were prepared by cork borer. 50 $\mu \mathrm{l}$ of CFS of fully grown VBEF2 was applied in the wells. Fluconazole $(200 \mu \mathrm{g} / \mathrm{ml})$ and sterilized DMSO were used as positive and negative controls. Experimental plates were incubated at $28^{\circ} \mathrm{C}$ for $3-5$ days.

\section{Antioxidant activity}

The antioxidant assay of the ethyl acetate extract of VBEF2 was carried out using stable 2, 2-diphenyl-2-picrilhydrazyl (DPPH) [18]. A stock solution of DPPH $(0.004 \%)$ was prepared for this assay. Another stock solution of ethyl acetate extract of VBEF2 was prepared by dissolving 0.01 g ethyl acetate extract in $1 \mathrm{ml}$ of methanol. Next, different concentrations $(5-150 \mu \mathrm{g} / \mathrm{ml})$ were made by mixing specific volume of endophyte stock solutions and fixed volume of DPPH stock solution and incubated in dark condition for 30 minutes. Finally, after incubation, optical density of each set was measured using spectrophotometer at $517 \mathrm{~nm}$. Methanol with DPPH solution $(0.004 \%)$ was used as the blank set in this assay. Ascorbic acid was used as the control in this experiment. Next, percentage of inhibition (POI) of each concentration set was calculated, from which the $\mathrm{IC}_{50}$ value of the ethyl acetate extract of VBEF2 was determined. POI of each set was calculated using the formula given below:

POI of DPPH activity $(\%)=[(a-b) / a] \times 100 ; a=0$. D. of blank set and $b=0 . D$. of each set.

\section{RESULTS AND DISCUSSION}

\section{Antibacterial activity of the endophytic isolates}

Among the 17 endophytic fungal strains isolated from the leaves of S. wallichii (Table 1), only VBEF2 exhibited very good antibacterial potentials. Its CFS produced clear zone of inhibition ranging from 10 to $20 \mathrm{~mm}$ against the Gram-negative as well as Gram-positive pathogenic bacteria. It showed more antibacterial efficiencies against the Grampositive bacteria compared to Gram-negative bacteria on the basis of the diameter of zone of inhibition it produced (Fig. 1). This was found may be due to the production of any antibacterial compounds that interfere with the peptidoglycan layers of cell wall of Gram-positive bacteria. The VBEF2 showed highest activity against $S$. aureus and lowest against $P$. aeruginosa. The test bacteria were found to be sensitive to ciprofloxacin and resistant to DMSO.

\section{MIC and the mode of action of VBEF2}

By counting the CFU of the test bacteria, the MIC values of ethyl acetate extract of VBEF2 were found to be $50 \mu \mathrm{g} / \mathrm{ml}$ and $150 \mu \mathrm{g} / \mathrm{ml}$ against $S$. aureus and E. coli, respectively. These results also attest the fact about the more antibacterial efficiency of the endophyte against Grampositive bacteria (Table 2). The mode of action of the ethyl acetate extract of VBEF2 against both $S$. aureus and E. coli was also determined by counting CFU of the both control and treated sets at every hour. Based on the growth pattern of the bacteria observed in the treated set, the activity of the VBEF2 extract was found to be bactericidal against both the bacterial strains. In the treated sets, the growth of the bacteria declined sharply due to the bactericidal activity of the extract (Fig. 2a and b).

\section{Antifungal activity of VBEF2}

The CFS of the endophytic strain VBEF2 was found to show excellent antifungal range as it produced clear zones of inhibition against all the four pathogenic fungi used. The antifungal potential of VBEF2 was determined based on the diameter of zones of inhibition produced by it. The antifungal potential of the endophyte was much higher against the plant pathogenic fungi, i.e., H. compactum and A. alternata. Moderate antifungal activity of VBEF2 was also found against $C$. albicans and A. parasiticus (Fig. 3). All the test fungi were sensitive to fluconazole and resistant to DMSO. C. albicans is the causal organism for oral and vaginal candidiasis, and A. parasiticus is the pathogen responsible for aspergillosis. Hence, the ability of VBEF2 in controlling these pathogens

Table 1: List of endophytic fungi isolated from the leaves of S. wallichi

\begin{tabular}{ll}
\hline Leaf S. No. & Endophytic fungal isolate \\
\hline Leaf1 & VBEF1, VBEF2, VBEF3, VBEF4 \\
Leaf2 & VBEF5, VBEF6, VBEF7, VBEF8, VBEF9 \\
Leaf3 & VBEF10, VBEF11, VBEF12 \\
Leaf4 & VBEF13, VBEF14, VBEF15 \\
Leaf5 & VBEF16, VBEF17 \\
\hline
\end{tabular}

S. wallichii: Schima wallichii, VBEF: Visva-Bharati endophyte fungal

Table 2: MICs of the ethyl acetate extract of VBEF2 CFS against S. aureus and E. coli

\begin{tabular}{lll}
\hline Concentration $(\mu \mathrm{g} / \mathrm{ml})$ & \multicolumn{2}{l}{ CFU $/ \mathrm{ml}$} \\
\cline { 2 - 3 } & S. aureus & E. coli \\
\hline Control & $1.2 \times 10^{9}$ & $2.1 \times 10^{9}$ \\
25 & $2.2 \times 10^{8}$ & $1.7 \times 10^{8}$ \\
50 & $1.8 \times 10^{5}$ & $1.1 \times 10^{8}$ \\
100 & $1.7 \times 10^{3}$ & $2.1 \times 10^{7}$ \\
150 & $3.1 \times 10^{2}$ & $3.4 \times 10^{4}$ \\
200 & $1.8 \times 10^{2}$ & $2.1 \times 10^{2}$ \\
\hline
\end{tabular}

CFS: Cell-free supernatants, S. aureus: Staphylococcus aureus, E. coli: Escherichia coli 


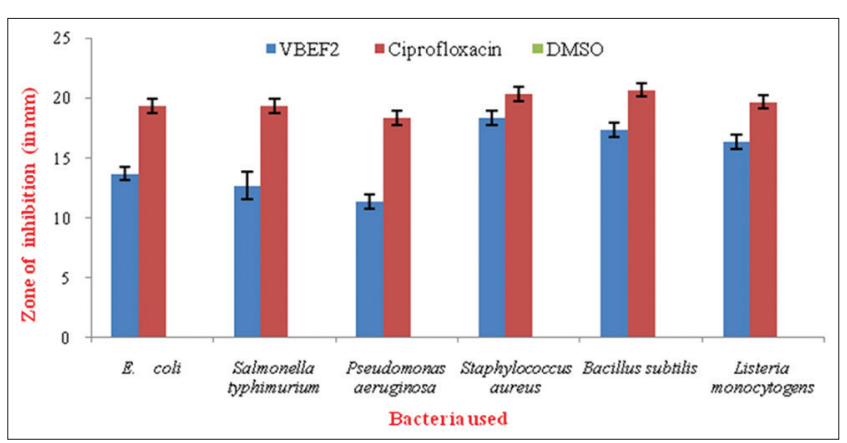

Fig. 1: Antibacterial activity of the cell-free supernatants of VBEF2 against six pathogenic bacteria

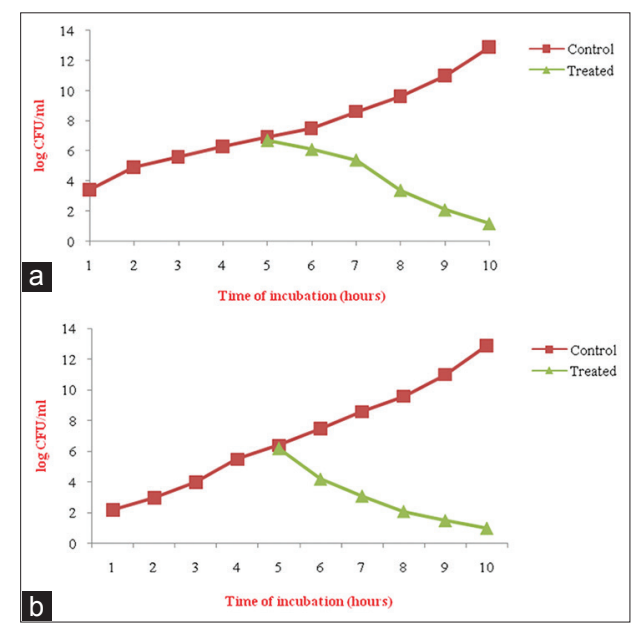

Fig. 2: Mode of action of the ethyl acetate extract of VBEF2 cell-free supernatants against (a) Staphylococcus aureus and (b) Escherichia coli

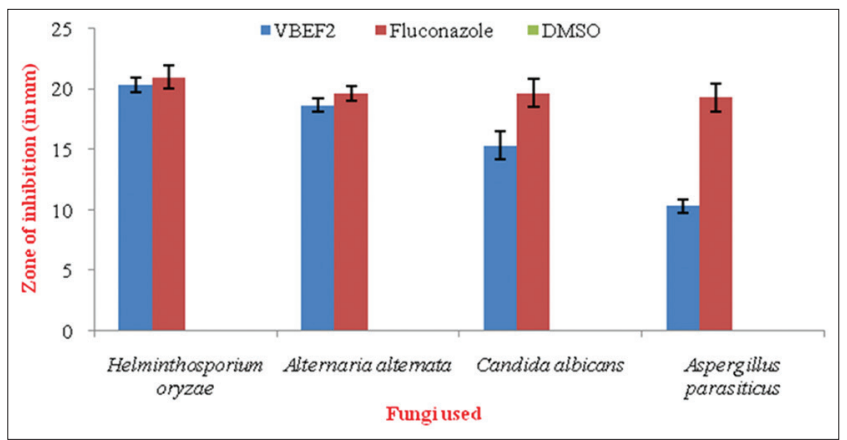

Fig. 3: Antifungal potentials of the cell-free supernatants of VBEF2 against four pathogenic fungi antioxidant activity of VBEF2

as well as the plant pathogenic fungi attests its applicability in the pharmaceutical as well as agriculture sector.

The ethyl acetate fraction of the CFS of VBEF2 showed very low $\mathrm{IC}_{50}$ value $(19.01 \mu \mathrm{g} / \mathrm{ml})$ in the DPPH scavenging antioxidant assay. This observation was considered as a good result as its $\mathrm{IC}_{50}$ value was found to be close with the $\mathrm{IC}_{50}$ value of the control ascorbic acid used $(8.5 \mu \mathrm{g} / \mathrm{ml})$. DPPH scavenging pattern of the ethyl acetate fraction of VBEF2 is represented graphically (Fig. 4). Plant extracts contain several phenolic compounds such as flavonoids, phenolic acids, tannins, and phenolic diterpenes which are responsible for the antioxidant effects [19]. Previous reports revealed that the phytochemicals with antioxidant activity may reduce the risk of cancer and also improve health conditions. Till now, many reports

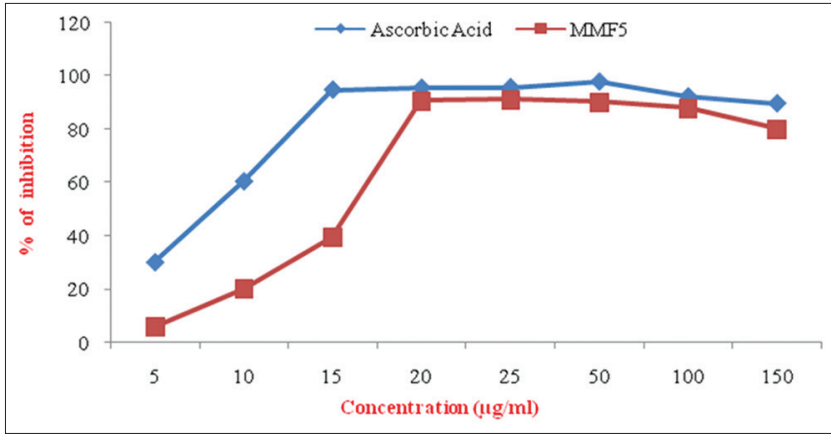

Fig. 4: Antioxidant potential of VBEF2 in DPPH scavenging assay identification of the isolate VBEF2

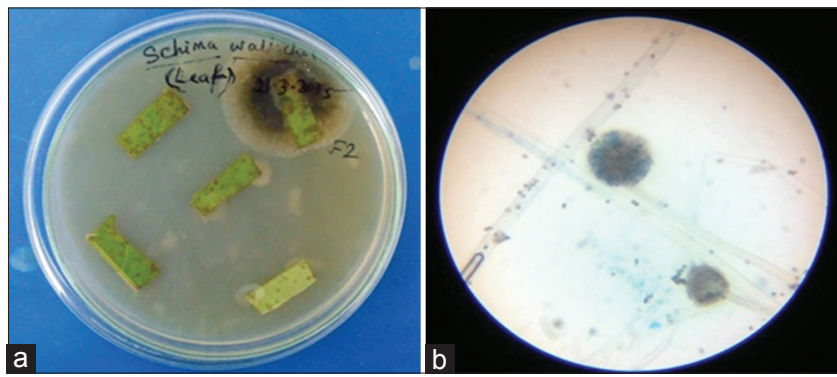

Fig. 5: (a) Colony nature and (b) microscopic view of VOBEF2 under compound light microscope

have been published regarding the antioxidant potentials of several isolates of Aspergillus [20].

The colony of the isolate VBEF2 was observed with blackish mycelia with grayish border in MEA plates which are very common features of Aspergillus colony. Besides, the presence of unbranched conidiophores with terminal globose vesicles covered by chains of conidia and simple septation in the vegetative mycelia is observed under microscope also helped to identify the fungus as a species of Aspergillus (Fig. 5a and b). Previously, an endophytic species of Aspergillus isolated from the leaf of Justicia adhatoda showed antibacterial activities against $S$. aureus, P. Aeruginosa, and E. coli [21].

\section{CONCLUSION}

17 endophytic fungi were isolated from the leaves of $S$. wallichii, and among them, only VBEF2 exhibited its antibacterial potentials against all the six pathogenic bacteria used. Its low MIC values with bactericidal mode of action against both $S$. aureus and E. coli also indicate its antibacterial efficiencies against Gram-positive as well as Gramnegative bacteria. The endophyte was also found to show excellent antifungal potentials against both plant pathogenic as well as animal pathogenic fungi. In the DPPH scavenging antioxidant assay, VBEF2 also showed very good antioxidant activity by showing low $\mathrm{IC}_{50}$ value. Hence, the Aspergillus isolate can be a great prospect in the pharmaceutical sector for its excellent antimicrobial as well as antioxidation potentials.

\section{ACKNOWLEDGMENT}

Authors would like to thank the University Grants Commission, India, for the financial support.

\section{REFERENCES}

1. Hirsch GU, Braun U. Communities of parasitic microfungi. In: Winterhoff W, editor. Handbook of Vegetation Science: Fungi in Vegetation Science. Dordrecht: Kluwer Academic; 1992. p. 225-50.

2. Costa FG, Zucchi TD, Melo IS. Biological control of phytopathogenic fungi by endophytic actinomycetes isolated from Maize (Zea mays L.). Braz Arch Biol Technol 2013;56:948-55. 
3. Maciá-Vicente JG, Jansson HB, Mendgen K, Lopez-Llorca LV. Colonization of barley roots by endophytic fungi and their reduction of take-all caused by Gaeumannomyces graminis var. tritici. Can J Microbiol 2008;54(8):600-9.

4. Maciá-Vicente JG, Jansson HB, Abdullah SK, Descals E, Salinas J, Lopez-Llorca LV. Fungal root endophytes from natural vegetation in Mediterranean environments with special reference to Fusarium spp. FEMS Microbiol Ecol 2008;64(1):90-105.

5. Freeman S, Rodriguez RJ. Genetic conversion of a fungal plant pathogen to a nonpathogenic, endophytic mutualist. Science 1993;260(5104):75-8.

6. Schulz B, Rommert AK, Dammann U, Aust HJ, Strack D. The endophyte-host interaction: A balanced antagonism? Mycol Res 1999;10:1275-83.

7. Purwantini I, Wahyono W, Mustofa M, Asmah R. Isolation of endophytic fungi from Artemisia annua, L and identification of their antimicrobial compound using bioautography method. Int J Pharm Pharm Sci 2015;7(12):95-9.

8. Sharma D, Pramanik A, Agrawal PK. Evaluation of bioactive secondary metabolites from endophytic fungus Pestalotiopsis neglecta BAB5510 isolated from leaves of Cupressus torulosa D.Don. 3 Biotech 2016;6(2):210

9. Stierle A, Strobel G, Stierle D. Taxol and taxane production by Taxomyces andreanae, an endophytic fungus of Pacific yew. Science 1993;260(5105):214-6.

10. Bhagobaty RK, Joshi SR. Antimicrobial and antioxidant activity of endophytic fungi isolated from ethnomedicinal plants of the "Sacred forests" of Meghalaya, India. Mikol Lek 2012;19:5-11.

11. Jayanthi G, Kamalraj S, Karthikeyan K, Muthumary J. Antimicrobial and antioxidant activity of the endophytic fungus Phomopsis sp. GJJM07 isolated from Mesua ferrea. Int J Curr Sci 2011;1:85-90.
12. Prabukumar S, Rajkuberan C, Ravindran K, Sivaramakrishnan S. Isolation and characterization of endophytic fungi from medicinal plant Crescentia cujete L. and their antibacterial, antioxidant and anticancer properties. Int J Pharm Pharm Sci 2015;7(11):316-21.

13. Awadh A, Ali N, Al-Rahwi K, Lindequis U. Some medicinal plants used in Yemeni herbal medicine to treat malaria. Afr J Tradit Complement Altern Med 2004;1:72-6.

14. Sarbadhikary SB, Bhowmik S, Datta BK, Mandal NC. Antimicrobial and antioxidant activity of leaf extracts of two indigenous angiosperm species of Tripura. Int J Curr Microbiol Appl Sci 2015;4(8):643-55.

15. Bauer AW, Kirby WM, Sherris JC, Turck M. Antibiotic susceptibility testing by a standardized single disk method. Am J Clin Pathol 1966;45(4):493-6

16. Ray B, Schamber R, Miller KW. The pediocin AcH precursor is biologically active. Appl Environ Microbiol 1999;65(6):2281-6.

17. Fernandez-Garayzabal JF, Delgado C, Blanco M, Vazquez-Boland JA, Briones V, Suarez G, et al. Role of potassium tellurite and brain heart infusion in expression of the hemolytic phenotype of Listeria spp. on agar plates. Appl Environ Microbiol 1992;58(1):434-8.

18. Braca A, Sortino C, Politi M, Morelli I, Mendez J. Antioxidant activity of flavonoids from Licania licaniaeflora. J Ethnopharmacol 2002;79(3):379-81.

19. Kumar U, Kumar B, Bhandari A, Kumar Y. Phytochemical investigation and comparison of antimicrobial screening of clove and cardamom. Int J Pharm Sci Res 2010;1(12):138-47.

20. Chandra P, Arora DS. Antioxidant activity of fungi isolated from soil of different areas of Punjab, India. J Appl Nat Sci 2009;1(2):123-8.

21. Prabavathy D, Nachiyar CV. Study on the antimicrobial activity of Aspergillus sp. isolated from Justicia adathoda. Indian J Sci Technol 2012;5(9):3317-20. 